\title{
The teaching reform of Pharmaceutical Botany Field Practice in teaching mode of competence-based
}

\author{
Jielian Wu, Yuping Guo, Wang ping \\ school of pharmacy, Jiangxi Science\&Technology Normal University, Nanchang China \\ 58997282@qq.com
}

Keyword: ability standard; Pharmaceutical botany; practice teaching

\begin{abstract}
Pharmaceutical botany teaching has the characteristics of strong intuition.Though long-term outdoor teaching practice in the field of pharmaceutical botany,we tried to have some teaching reform from the aspects of practice based construction,teaching content system,practice teachers and practice time,so as to adapt to the "Ability Standard"and field practice of Pharmaceutical Botany.At the same time,we tried to improve the combination effect of theory teaching and experiment teaching as well as field exercitation.As a result,to figure out a new way that has great teaching effect and can apply to social demand.
\end{abstract}

\section{Introduction}

"Ability standard"[1]is the ability centered education, is our country at the end of the last century from the introduction of the Canadian education model.Because of the difference between Chinese and Western culture and the traditional teaching mode, the teaching mode has not been fully integrated into the Chinese teaching,In recent years, with the development of science and the needs of talent, our higher colleges and higher vocational colleges will be integrated as the "ability standard" mode gradually into specific China education, the Chinese, changed the past to teaching based education pattern, gradually formed the occupation ability training based education mode.The occupation education mode with ability as the center, from the talent training scheme, curriculum implementation and teaching, performance appraisal and other aspects, is to cultivate students' occupation ability and adapt to society as the main line, pay attention to students' comprehensive quality and practical ability to solve the problem of high [2].

"Pharmaceutical botany" is an important professional basic course of pharmacy specialty, which has the characteristics of practicality and intuition.To learn this course is very important for the study and Research on the development of medicinal plant resources in the study of the identification of Chinese medicine and the cultivation of traditional Chinese medicine and other related subjects. The field practice of medicinal plants is a very important practice link in pharmacy undergraduate education, and it is an important teaching link of medical botany theory. It is a comprehensive application and combination of theory and practice.The purpose is to cultivate students' rigorous learning attitude, the ability to solve practical problems and the spirit of solidarity plays a very important role. At present,most schools take the “According to fill a prescription"mode of practice,practice teaching is simple to recognize that medicine, this guilding ideology will lead to single field practice; lead students just follow the teacher's requirements the completion of the internship, students in the whole process are often in a passive position, leading to students' lack of initiative and enthusiasm, easy to make students have antagonistic and tired of learning mood, especially not suitable for the study of the course of "Pharmaceutical botany"[3-5], is not conducive to the cultivation of student's independent thinking, the ability to analyze and solve problems, and thus fails to achieve the teaching purpose of practice.Therefore, in order to meet the requirements of quality education, to cultivate students' practical ability and innovation ability as the goal, it is imperative to reform the practice teaching of medicinal botany. [6-8]. Therefore, the author has long been engaged in "Pharmaceutical Botany" teaching practice, in view of the field at present "Pharmaceutical Botany" practice, constantly summarize the theory teaching and practice teaching, through field practice base construction, teaching content system, training of teachers, assessment 
methods and field practice time in four aspects has carried on the discussion to the existing teaching practice .The aim is to improve the quality of field practice and to improve the students' knowledge and ability.

\section{Further strengthening the construction of field practice base}

The medicinal botany in Mount Lu on the field practice content is to complete a 2 week practice, students must know 200-300 species of medicinal plants, but, and they can not accept too much in the short term, resulting in a waste of cost.The research group decided to arrange for the 4 time in the field of teaching and learning in the course of the theoretical knowledge of medicinal plants; this stage is a learning process for students to understand the perceptual knowledge of medicinal plants.This requires that we must establish a field practice base between classes, the study decided to set up the campus and campus around the two types of practice base.Firstly, to strengthen the construction of medical plants in the school practice base-drug count, During the course of classroom theory theaching, use of the break time, with students in the campus base scene class.This medicinal plant "live lectures" in the classroom use of the site of the botanical garden plant resources to identify the characteristics and structure of various types of plant tissues and organs, so that the teaching content more intuitive, vivid, image, to a large extent,improve the teaching effect. It provides an experimental base undertakes research for full-time teachers.Secondly, the establishment of schools around the medicinal plant field practice base -- Meiling medicinal plant field practice base,Meiling is a mountain near the school, superior geographical environment, the formation of plant species, communities and ecosystems are rich. Therefore, in order to better accomplish the task of teaching practice. So increase the drug court and Meiling as a training base, a better combination of theory and Practice.

\section{Construction of the field practice teaching content system in order to cultivate students' professional ability'}

The traditional way of the field practice is to say that the teacher while walking and students record, this practice mode on the surface has a certain size, but in essence, it has little effect[9]. In the whole process of practice, ignoring the students' initiative, enthusiasm and innovation ability of the training, More serious is that this practice led students can only learn some surface, fragmentary knowledge, the whole practice process of the lack of skills training. In view of the above traditional practice shortcoming, this research group based on "Ability Standard" uses the interactive practice method, and on this basis increases three aspects of teaching content.Firstly, To guide students to the collection of medicinal plants for indexing, to cultivate students' ability to independently recognize new medicinal plants[10]; Secondly, to guide students to grasp the effective ingredients of medicinal plants and preparation methods, to achieve the combination of theory and practice, but also lay the foundation for the follow-up Specific-job Training. Finally,perfect in the Mount Lu of the field practice teaching, the author and co written $<$ Mount Lu botanical expert medicinal plant Field Practice Handbook>, focuses on the common practice in the field of medicinal plants, so that Mount Lu medicinal botany field practice more perfect[11].The teacher no longer simply taught, but take inspiration, questioning interactive ways to carry out practice, guide the students to learn the application of botanical terms to describe the plant characteristics, identification of plant species, understanding common medicinal plants, understand its pharmacological effects. At the same time, under the guidance of teachers, students will make a good display of plant specimens in the campus, enrich the campus culture. Also increases students' sense of achievement.

\section{Construction of "ability" as the center of the "double qualification" teaching staff.}

The new teaching content system needs a new "Double Teachers" teaching staff. With "capacity" as the center of the "double" teachers construction through the practice of "going out" and "please come in" approach.Training the high level of field practice teaching staff is the key to the success of 
the internship, teachers should not only have a solid theoretical knowledge, but also have a wealth of field practice teaching experience[12]. Over the years, the school has always attached great importance to cultivating "Pharmaceutical Botany" field practice of teachers, the professional skills of teaching teachers were improved by the way of on-the-job training of the field practice full-time teacher,through the "pass, band, help" to help young teachers to grow rapidly in order to ensure that the follow-up field practice continues to carry on.Practice has proved that this kind of "Double Teachers" teacher troop mechanism has provided the first teaching and the scientific research data for the college, and the combination of theory and practice,It not only improves the classroom teaching effect, but also helps to train the young teachers.

\section{Change the assessment methods to stimulate students' professional potential}

In the past the end of the internship of plant identification examination, investigation of this evaluation emphasis on knowledge and ignore the ability, therefore, the task of the group from four aspects of the practice of assessment[13].Firstly,To focus on simple identification of drug assessment approach to "fun style", that is, the form of side edge of the assessment of Medicine; Secondly, each group chooses a kind of medicinal plant, and designs the extraction and preparation method of the effective components of the plant; thirdly,The internship period of all plants produced CAI internship courseware; Finally, give students some exploratory tasks, such as the investigation of poisonous and medicinal plants in Mount $\mathrm{Lu}$, the investigation of common medicinal plants in Mount Lu, and the use and protection of Mount Lu,Each group of students according to the research plan and the practice content, consults the related material for the practice report and the paper writing accumulation material[14].With a mission to purposefully participate in internships, can improve the students' initiative in the field practice, such as training the practical ability of students, but also conducive to cultivating and improving students' innovation ability and team cooperation ability

\section{The reform of field practice time}

The traditional mode of practice requires students to fully grasp the morphology, classification, pharmacological knowledge of 200-300 species in 2 weeks, master so much more knowledge in a short period of time, there will be little effect.In order to improve the teaching effect.After the study, the author adjusted the internship time as follows:first, separate field practice, namely the use of the theory of classroom and after-school time to lead students to the field of teaching and the surrounding Meiling on campus; second, focus on field practice, namely the end of may began, in Mount Lu on the 2 week internship, this time coincided with the flowering plants, can observe anatomy and write the formula of flower plants.The survey found that after the reform, the students by rote master plant characteristics of poor results, after the reform, the students through observation and anatomical characteristics of plants are easy to remember.The adjustment of time allows students to really master the difficulties in the classroom, and to maximize the effectiveness of field practice.

Jiangxi is a large Chinese herbal medicine producing areas, the traditional Chinese medicine is the pillar industry in Jiangxi, occupies an important position in Jiang xi.The author uses the "ability standard" mode of vocational education practice teaching of "Pharmaceutical Botany" field, in-depth exploration on teaching contents, practice teaching method, teachers, assessment methods and other specific aspects, and through the teaching reform, cultivate students' ability for medicinal plant identification and quality evaluation and other aspects. With pharmaceutical professional other courses, for Jiangxi and the national pharmaceutical enterprises to cultivate qualified talents with real practical solution to the problem

\section{Conclusion}

According to the "Ability Standard" teaching mode of "Pharmaceutical Botany"field practice 
in-depth reform of the teaching mode, greatly stimulate the herbal knowledge students' interest and enthusiasm in learning, has obtained the good teaching effect. Through the occupation education mode ability centered implementation "Pharmaceutical Botany"field practice, not only enhance the students of medicinal plants of intuitive understanding, but also cultivate the students' scientific attitude and the ability to solve problems, and the students' comprehensive quality and practical ability to solve problems.

\section{Reference}

[1]Chen.Juzhen.The influence of two vocational education modes in the world on the development of Higher Vocational Education in China,J.Vocational Education Research.2006.3( 124-125).

[2]GongXue.Analysis and Enlightenment of international vocational education research activities,J.Vocational Education Forum,2011.10(81-82).

[3]Yin HaiBo,WangBing,XuLiang.Practice teaching system reform of medical botany,J.Journal of Liaoning University of Traditional Chinese Medicine,2010.3(80-83).

[4]Cheng Yingxia.New mode of field practice teaching in Botany,J.Journal of Hebei Vocational and Technical College,2004, 4(1):36-37.

[5]Zhang Yingmei,Cheng Qiang.Exploration and Practice on the field practice of "mobile" biology,J.Higher Education of Sciences,2003(5):80-83. [6]Lin Changsong.New mode of field practice teaching in Botany,J.Biology Teaching,2008, 33(10):17-18.

[6]Cheng Mosun,Li Junmin.Practice and Discussion on the teaching reform of Botany field practice,J.Journal of Biology,2003, 20(3): 43-45.

[7]Zheng Yunxiang.On the reform of Botany Experiment Teaching in Colleges and Universities,J.Journal of Hengshui University,2007, 9(3):110 -112.

[8]Xu Yufeng,Wang Wenhe,Zhang Chunyu,et.al.Carrying out the principle of heuristic teaching and improving the teaching effect of Botany,J.Higher agricultural education,2003(5):43-44.

[9]Ma ChunYan,PuJun,Fu Liang.The mode of field practice of Botany,J.Journal of Shenyang Normal University: Natural Science Edition,2007,25(2):286-288.

[10]Xu Lei,Wang ZhiPing,Ye CongJing.Analysis and reform measures of the field practice of medicinal botany,J.Asia Pacific Traditional Medicine,2013.7(9)222-223.

[11]Xu JianGuo.Discussion on the new mode of geography field practice and the construction of practice base in Normal University,J.Experimental Technology and Management,2003,20 (5) : 115-118.

[12]Cheng Yan,Liu WanJu,Zheng XiaoLin.Teaching reform and practice of Botany field practice,J.Journal of Biology,2010， 27(3):98 -100.

[13]Cheng JiuMiao,Wang ZongYing,Liu FuCheng.A preliminary study on the reform of physical geography field practice mode and content in Mount Lu,J.Journal of Anhwei Normal University: Natural Science Edition,2000,23 (4) : 383-385.

[14]Zhang MeiPing,Han WenGe.Innovation and practice of the teaching method of "botany" field practice,J.Journal of changchun university of science and technology,2012,7 (1) : 205-206. 